\title{
Drama in Education: It's Effectiveness in Acceptance of Racial Diversity in a Multicultural Classroom
}

\author{
Nick Mavroudis $^{1 *}$, Alkistis Kondoyianni ${ }^{2}$
}

\begin{abstract}
${ }^{1}$ Teaches Physical Education at the 87th Multicultural Primary School of Athens, He has also studied acting at the Drama School of the National Theatre of Northern Greece. He holds a PhD in Drama in Education from the Faculty of Physical Education and Sports Science, National and Kapodistrian University of Athens

${ }^{2}$ Professor of Drama in Education at the Department of Theatre Studies, School of Fine Arts, University of Peloponnese. She participates at research groups in many countries and has given lectures and workshops worldwide. She is the author of 39 books for children and educators
\end{abstract}

DOI: $10.36347 /$ sjahss.2020.v08i09.008

| Received: 10.09.2020 | Accepted: 17.09.2020 | Published: 25.09.2020

*Corresponding author: Nick Mavroudis

\section{Abstract}

The purpose of this article is to demonstrate the contribution of a Drama in Education program to respecting and accepting racial difference. The program was implemented for seventeen (17) weeks at a rate of 2 hours per week, with twenty-one $(21)$ children attending the $87^{\text {th }}$ intercultural primary school of Athens. This research is a case study that uses interviews, observation, the researcher's diary and evaluations and self-evaluations of the participants as research tools. The results of the research demonstrate the positive impact of Drama in Education on respect and acceptance of racial difference, highlighting it as an important educational tool that contributes to the management of cultural inhomogeneity in the classroom.

Keywords: Drama in education, racial difference, multicultural classroom, identity.

Copyright @ 2020: This is an open-access article distributed under the terms of the Creative Commons Attribution license which permits unrestricted use, distribution, and reproduction in any medium for non-commercial use (NonCommercial, or CC-BY-NC) provided the original author and source are credited.

\section{INTRODUCTION}

Racial identity, which is part of cultural identities, refers to the characteristics that a collective inherits from its common ancestors. As it is attributed to its holder at birth, it extensively determines the latter's way of life [1]. Racial identity is immediately perceived in both public and private contexts and has been used much more frequently than other identities as a starting point for different treatment of people [2]. Historically, groups that have been "created" to be racially diverse have often been subject to policies of exclusion and discrimination by dominant groups due to the risk of racial mixing, which threatens the homogeneity of a collective [3]. That is why racial categorisation often leads people to forget that individual identities are complex and diverse - that they have enthusiasm that does not stem from race or nationality and that their interests and choices cross any national or racial boundaries [4].

In the educational context, the presence of racially diverse students has often been seen as threatening the myth of racial purity and racial superiority of the nation that characterises most of the world's dominant groups [3]. However, students are not only members of specific subcategories of the human race [1]. They are personalities who fall into a number of possible categories and can easily recognise similarities and identify with a wide variety of other people's identities. That is why the identities we need should recognise both the central position of difference in human identity and the fundamental moral unity of humanity [2]. In view of this perception, education needs to recognise all the numerous aspects of human identity. Respecting an individual's personality regardless of the influences of the person's culture and encouraging positive interactions among all children without exception should be a priority [5-7]. Our position is that the school needs to foster in its students the perception that they live in a world that they share with others. This means that the activities of others affect their own lives in the same way that their own actions have an impact on the lives of others. Therefore, they are required to work for a society with social justice in whom racial (and any other) discrimination has no place [8-10].

1 The term race is used in this article to denote a social category and to describe populations that share some common characteristics, without implying any biological background. 
Thus, managing racial difference in education calls for an intercultural pedagogy which, by hindering the operation of authoritarian relations within the school, may contribute to the establishment of cooperative relations between those involved. Such pedagogical programmes relate to interactions among pupils, as well as to teacher-student interactions and to empower learners, such programmes are based on racial equality principles and the desire to educate young people in a way that ensures their participation in a democratic society [3]. As cultures survive only when they derive the power to transform from criticism and dissension, each individual must be able to channel that power, which can be greatly enhanced through cultural exchanges and interactions with others [11].

As a pedagogical framework, Drama in Education can cultivate all the skills required for the fruitful coexistence of participants trying to interact in a society characterised by all kinds of otherness [12]. According to O' Farrell [13], its activities resemble those of ritual. They free participants from the conventions of everyday life and lead them to a place where reality can be deconstructed and safely rebuilt to create an awareness of things that affect the participants' worldview. Drama in Education offers children the opportunity to understand their perceptions, beliefs, beliefs, attitudes, reactions, and especially their emotions through active listening, observation, empathy, and the detection or identification of emotions developed within a role. When students try to create a role, they are called upon to think about how to react and act as other people by looking back at their real or imaginary emotional experiences [14]. The path from dramatic creation to personal reality and vice versa, brings to light unexploited manifestations of the self, in an effort to realise the roles that everyone plays in their lives, to release them, while helping to gain flexibility, tolerance and understanding. The discovery of the points of convergence and deviation of the self with others in the context of social interaction finally promotes the repositioning of the relationship one has with both oneself and others [15].

\section{Purpose}

The purpose of this article is to investigate the effects of the implementation of a Drama in Educationthemed intervention on the acceptance of racial difference, in a class attended mainly by refugee, immigrant and minority children.

\section{METHODS}

\section{Research hypotheses}

The main research hypothesis refers to the question whether this Drama in Education program will have a positive effect on the acceptance of racial difference in a class with children from different cultural backgrounds.

\section{The participants}

The participants chosen by draw to ensure randomness were pupils of class $\mathrm{D}$ and $\mathrm{E}$ of the $87^{\text {th }}$ intercultural elementary school of Athens, located in the area of Kerameikos. The researcher has been part of the teaching staff of the establishment as a Physical Education teacher since 2004. The study participants included 8 boys and 13 girls aged 10-12, from lowincome and financially disadvantaged families. More specifically, nine (9) pupils are from the Muslim minority in Thrace, seven (7) pupils from Albania, one (1) is from Syria, one (1) is from Afghanistan, one (1) is from Bulgaria and two (2) are of Greek origin. Of the above pupils, 6 (six) are Romani, five (5) Romani come from Albania and one (1) is from the Muslim minority in Thrace. Eighteen (18) children are Muslim and three (3) are Orthodox Christian.

\section{METHODOLOGY}

The research tools used were interviews, observation, the researcher's diary and the evaluations and self-evaluations of the participants. This research is based on qualitative methodology and is a case study.

Interviews were chosen as a research tool because since the mother tongue of the majority of pupils is not Greek, children could answer with more spontaneity than in a written questionnaire. The interview is also a reliable and adaptable tool that allows the researcher to investigate in depth the subject under consideration, because it also offers the ability to collect information through sensory channels such as verbal, non-verbal communication and listening [16]. The interviews were individual so that the children were not influenced by their classmates and took place in a quiet space, in the school library. The children answered the same questions, both before the implementation of the program (initial interviews) and after it was completed (repeat interviews). The interviews were semi-structured, with open-ended questions, leaving room for further investigation. Respondents were thus able to process in depth and better explain their views [17]. The interview questions were based on the questionnaire used by Danochristou [18] and Sextou [19] in their own research.

Observation in the research was participatory. The researcher observed the children's behaviours by participating fully in the program's processes, aiming at a more substantial understanding of the relationships among pupils [20]. The teachers of both classes that were involved in the research took part in the observation. The teacher observers did not participate in the activities (complete observers) so they could more accurately observe what was happening by recording their own view of things at the time of the actions [21]. One teacher observer is also a psychologist with extensive experience in observation, while the other teacher was trained by the researcher in observation in Physical Education classes. The teacher-psychologist 
also had the role of critical friend $\left[{ }^{2}\right]$. The critical friend took a neutral stance towards the research and with the suggestions and the critical look at what was happening, she contributed to the further credibility of the project $[22,23]$. The researcher recorded his own observations immediately after the end of each meeting. The observation key used as the guide for what exactly was observed was based on Danochristou [18] and Katsarou [24] research. It is estimated that both during the interview and during the observation, the children's behaviour was not affected by the presence of researchers and observers in the area, as they are familiar faces, their teachers, with whom they have developed a long-term relationship.

The researcher recorded his observations in the researcher's diary. Such diaries can feed research with important information about participants and their attitudes toward activities [25]. In addition, the diary allowed the researcher to investigate methodological issues such as the effectiveness of the interview schedule, to note non-verbal aspects of the participants' behaviour, to refer to his assumptions and beliefs and how they affected the research, forming a useful organisational aid for the research process as a whole [26].

Data for the research were collected from the evaluations of the participants for the program as well as from their self-evaluations, which the children provided every 3-4 meetings through the techniques of hot chair and telephone conversations. The views, attitudes and assessments of the children for the intervention were recorded in the last meeting, during which an overall (written and art-based) evaluation of the program was made. This was also achieved through the discussion that took place at the end of each workshop. In this way, the data in the research were collected from three different sides: that of the researcher, the observers and the participants.

\section{The Drama in Education program}

The investigation began in October 2014 with the initial interviews of the children. Seventeen (17) meetings followed in which the researcher, who is also a drama teacher and actor, hosted the activities of the program. The research was completed at the end of the repeat interviews in early June 2015. The meetings took place once (1) a week and the duration of each meeting were two (2) teaching hours in a row each time. The main goal of the activities was to develop the participants' social and emotional skills that will enable

${ }^{2}$ The term critical friend was first used by Stenhouse in 1975, suggesting that a trusted person could act in support of the researcher by working with him or her during the research. The critical friend's role is to listen, ask questions, discuss with the researcher, to clarify the latter's intentions and give honest and impartial feedback [22]. them to respect and accept the national, religious, linguistic and racial diversity of their classmates. The program was implemented in the school's theatre. It included psychomotor activities, theatrical plays, techniques and exercises from the Theatre of the Oppressed, improvisations, dramatisations, role-plays, techniques such as the "hot chair", "telephone conversations" and writing texts.

\section{RESULTS AND DISCUSSION}

The findings from the answers in the interviews after the completion of the intervention, as well as from the discussion that took place at the end of each meeting, but also from the children's evaluations of the program demonstrate a positive shift in the pupils' views regarding the acceptance of racial difference, confirming our research hypothesis. Focusing on the question of whether children would sit at the same desk with a child from Africa, there are children who in both initial and repeat interviews justify their positive response, referring to the positive experience they had in the past from their contact with a little girl with black skin colour, named A..., who was in their class.

P2[3]: "Yes, A... who left, was from Africa and she was black, I sat at the desk with her and she didn't do anything to me, she was very quiet." $\mathrm{P} 14$ : "Yes, with A... we were friends in third grade." P5: "Yes, I sat with A... Just because she's from Africa doesn't mean that anything is wrong with her." P10: "I would sit down, because I like these girls' hair. We had A..."

Invoking the experience of knowing A... was also observed at the fifteenth $\left(15^{\text {th }}\right)$ meeting. The children dramatised a story in which a child from Africa faced a difficult situation due to his difference in skin colour. Although two years have passed since A... left the class, in the discussion many children recalled the positive memories they had from the contact with her, "about how good of a girl she was", "about how sad they were and how much they cried when she left", to conclude "that skin colour plays no role in a person's character" and that ultimately "character is what matters. In this case we see that the personal identity prevailed over the collective and that the close acquaintance and frequent contact of children with racial difference had a positive effect on their behaviour. It activated critical thinking processes and probably contributed to the fight against stereotypes, as contact was a point of reference in the participants' responses. This case is confirmed by Allport [27] and researchers Pettigrew, Tropp, Wagner and Christ [28], who point out that frequent contact with people from different cultural backgrounds can improve their interpersonal relationships. In fact, the closer the contact, the greater the chance that it will lead to more substantial changes in their behaviour [29].

${ }^{3} \mathrm{P}=$ pupil 
The above assessments are reinforced by the fact that when children are asked in the initial interviews about how they feel when they meet people from Africa on the street (with whom they do not have frequent contact and acquaintance), the participants, ignoring their personal identities, attribute specific qualities to these people:

P4: "I think they are Negroes and I am afraid of them. I think they can do something bad and I'm afraid of them, if they were white I wouldn't be afraid". P10: "They are on the street, they catch and kill you. When I see black people, I am scared and leave. I am afraid of the old black people, not the young ones. I'm afraid of them when they look at me. They will take my heart and give it to others, that's what my mum told me". P14: "When they sometimes pass by with their carts, I'm afraid that they will rob me and I leave, because I'm a little scared of them". P18: "I think that they're sick, that they're like ghosts and I'm scared".

Marrota [30], states that the fear of the unknown stranger seems justified, because while diversity should help the identity to recognise itself through it, it often turns into fear of the unfamiliar, the foreign, the different. Singh [31] also estimates that all human beings have an innate tendency to seek intimacy in familiar faces, as what is unknown is probably dangerous for them and should be avoided. This may justify the fear of a different racial identity that is pervasive in the children's responses. The above responses of the participants seem to agree with Appiah [3], that racial identities are immediately perceived, both in private and in public, leading people to more easily forget that identities are much more complex and diverse. That is why when we seek to identify biological races with special qualities and categorisations, we move away from scientific truth [32].

However, frequent contact and interaction did not have the same effect in the case of Romani pupils. Although within the group, as well as throughout the school, there are pupils of Romani origin and there is daily contact with them both in the courtyard and in the classroom, the situation is more complicated. In the initial interviews, when children were asked if they would sit at the desk with a Romani classmate, we came across phrases such as:

P5: Little gypsies [4] can be annoying, they can take your books, and they can make fun of you and more". M6: "I wouldn't want him to have lice, I wouldn't sit with him”. P12: “... some gypsies tell a lot of lies and if I sit next to them and they talk to me, the teacher will punish me instead of them. They are very smart and steal our minds". P16: "I wouldn't sit down

${ }^{4}$ The children used the term gypsy instead of Romani and this term was retained in their answers. and play with her, because, sir, gypsies swear a lot when they talk. When we sit upstairs they swear".

P17: "No. I'd rather sit with N..., rather than with a gypsy”. P19: “... I wouldn't want him to swear in the gypsy language”.

A typical example of the situation a Romani pupil (P4) experienced at school is his response when referring to his experiences at school:

"When I first came to school when I was little, some kids bothered me. They said the school was full of gypsies... they were Turks, I was afraid of them".

It has been observed that despite daily interactions with Romani children, many participants attribute stereotypical traits to the Romani language and identity, such as that the Romani swear, make fun of, lie, and harass. Gkotovos'[33] view that stereotypes that the natives reject about themselves are attributed to the Romani's fixed qualities are thus confirmed. Pantazis and Marouli [34] also report that the Romani's negative stereotype often includes the assumption that they are dangerous. Such perceptions seem to be widespread among children and perhaps for this reason the negative climate within the group is also observed. However, following the positive impact of the intervention, it can be seen that in the repeat interviews stereotypical phrases such as those mentioned above are reduced. We find that three (3) pupils (P6, P7, P14) in the final interviews justify their favourable attitude towards the issue, referring to the close relationship they have with Romani classmates:

P3: "Yes, M..., he is a gypsy, in Bulgaria I was sitting next to gypsies". P6: "I'm sitting with a gypsy girl, A..., I have no problem”. P7: "Yes, I would sit with them, I wouldn't mind. After all, Andreas is sitting next to me". P14: "Yes, I sat with $C$... in fourth grade. They are also people, children, they want friends, I have no problem".

This raises the possibility that if there was a lack of frequent interaction and daily contact among the children within the school, the results in the initial interviews might have been more negative and the observed improvement in the situation after the intervention less significant. The strength of the stereotypes seems to be confirmed in a strong way in the case of P17. When the pupil in question is asked, he answers that he only trusts M... (Romani) in the entire class to tell him his secrets, revealing a very close relationship with a boy with a Romani identity, while when asked, if he would sit with a Romani at the same desk, he replies: "No, I don't speak the gypsy language. He may be cursing and I don't understand. M..., with whom I was sitting at the desk, is not a regular gypsy, because he speaks Greek". In other words, P17, among other things, perceives the knowledge of Greek by a 
Romani person as an indication of a non-regular gypsy and who, in fact, as a non-regular gypsy, could sit with him at the same desk.

Attempting to further decode the particularly negative view of the Romani people by the participants, it should be borne in mind that the majority of children who attended the research process came from immigrant families and from the Muslim minority in Thrace. It is very likely that the children themselves will be treated in many cases as others and will be socially excluded and discriminated against. Thus, in order to reduce the burden of social prejudice, referring to the even more socially degraded group of the Romani, they are more likely to show prejudice and negative emotions than children belonging to the dominant group. Perhaps this justifies the fact that when faced with a child from Africa, with whom there is no the direct social competition that exists with Romani pupils, children hold a more favourable attitude. In this case, Dragona [35] confirms that stereotypes work in ways that confirm existing power relations within society, legitimising the prestige of social groups over others.

Of course, it is extremely difficult to change data based on social prejudices with a single intervention program. Govaris, Nioti and Stamatis [36] point out that already from infancy, children pay attention to the indications of race and after the age of about four (4), they are aware of this categorisation. In fact, those who have been fed with racial prejudices by the family are deeply influenced by their parents' culture and find it very difficult to change their views, as they often adopt the parental view of things as a means to survive. Thus, the pupils, as carriers of the stereotypical images and perceptions that prevail in their social becoming, learn those categorisations that have value for the environment in which they grow up. In fact, this determines the criteria by which the evaluative ranking of the different groups is made, as well as the behaviours that are considered appropriate towards each group. This is why the concept of race appears early in environments where racial categorisation is of particular importance [37].

The program sought to create a network of interpersonal relationships that fights one-dimensional views and cultivates values that advocate a positive attitude toward racial difference and the creation of a universal solidarity for all human beings on a global scale [38]. A special contribution in this direction was brought by the activity of the Council, in the eleventh $\left(11^{\text {th }}\right)$ meeting. Through the group's consultation on whether to accept two sheep of a different colour in their herd, the children were encouraged to take a critical stand against constructed images of the other and to test dominant categorisations and patterns of behaviour. According to the observations, the group of children who did not want the sheep, revealed that they were afraid of them, that they did not want them because they are were black, because they would eat their food, they would be dirty, and they would steal and destroy their toys. In the discussion, arguments were heard from the opposite side that promoted an open dialogue that challenged the one-dimensional interpretation of the event, while cultivating flexibility in thought, active listening and solidary intentions. Typically, a member of the group stated that: "just because the sheep are black doesn't mean they're going to steal or destroy our toys", while the question: "Would you like to be in the place of the black sheep?" was the catalyst for the children's decision to accept the black sheep, demonstrating the development of empathy as a primary skill in shaping acceptance of racial differences. Empathy as a skill seems to have played a very important role in the twelfth $\left(12^{\text {th }}\right)$ meeting. The children negotiated racial difference through the story of a child from Africa who was not accepted into the school. In the stage performance of the story it was noticed that there were several pupils who were turned from spectators into what Boal [39] calls spect-actors, daring to ask to continue one of the roles on stage, proposing their own version and vision about the problematic situation that was taking place. Recognising their own human condition in the hero or heroine through the processes of empathy, the children intervened in what was happening, trying to find the right way to react and provide a solution by turning the stage space into a rehearsal space for future action in real life [40, 41]. As mentioned in the researcher's diary, but also in the observer's observations, there was a very dynamic climate of support and solidarity towards the protagonist and phrases such as: "How would you like it if they did not want you because you're black?", "What does it matter if the child is black, we're all black", "and nobody likes to be rejected".

The case of a girl who went on stage and defended the child in a strong manner was also recorded, stating how when she went to Germany for a short time she felt bad about the way she was treated and that from now on, anyone who behaves badly to their new classmate would be dealing with her, a phrase that won applause from the rest of the group. In the ensuing discussion, the group tried to find out the real reasons why the protagonist was not accepted, concluding that it was because the children did not know each other. Reference was also made to the institution of slavery, on whose existence, as it turned out, the majority of pupils did not have prior information. A typical case for the special impact that the event had on the participants is embodied by P16. In the repeat interviews, when asked to talk about the programme he attended, he refers to the specific activity, saying: "I liked that we did it once for a child who was not wanted, because it had a different colour. It got me thinking". 


\section{SHORTCOMINGS AND LIMITATIONS OF THE RESEARCH}

The research is subject to the following shortcomings and limitations: The school's dropout rate, which is a characteristic element of the $87^{\text {th }}$ intercultural primary school of Athens, had an impact on the number of participants. Thus, while in the first meetings the participants were twenty-five (25), over time the number of participants decreased to twenty-one (21) children. Failure to authorise videotaping may have had a negative effect on the collection volume of the research data. Finally, further research may be useful to determine the positive impact of the program in the long run.

\section{CONCLUSION}

The purpose of this article is to demonstrate the contribution of Drama in Education to respecting and accepting racial difference. As mentioned above, it is very difficult, of course, to change attitudes and behaviours that based on established perceptions with a single intervention. However, the program we implemented provided the children with opportunities to activate critical and flexible thought processes, to express their feelings, to cultivate active listening, to engage in emotional processes, in order to create cracks in their unbending beliefs. It is therefore confirmed that values and ideals that place human beings at the centre of interest can be cultivated through education. The non-competitive nature of Drama in Education, the rich collaborative experiences and the multiple forms of interaction it offers make it an irreplaceable educational tool. Through its activities, participants develop the socio-emotional skills needed to disconnect from themselves and show interest towards the other, as demonstrated by this research. When people express their solidarity towards the other that is close to them, they are trained to see humanity as a whole [42]. Moreover, this course is continuous, evolving and progressing without dividing lines and borders. From the personal to the collective, it transcends the borders of the country and encompasses the other country, the other religion, the other culture that has similarities, but also differences with ours. It includes those who love, hate, claim, fight for tomorrow, are hungry, kill, remember, just like ourselves. The individual this becomes a conscious and active part of the world's identity. So small, but so important at the same time [43].

\section{REFERENCES}

1. Morning A. Ethnic classification in international perspective. Population Research and Policy Review. 2008; 27(4): 1-35.

2. Cummins J. Language, power and pedagogy: Bilingual children in the crossfire. Clevedon: Multilingual Matters. 2000.

3. Appiah KA. "Identity, authenticity, survival: Multicultural societies and social reproduction," in
Multiculturalism, ed. Gutmann A, 149-164. New Jersey: Princeton University Press. 1994.

4. Appiah K. A. Race, culture, identity: Misunderstood connections. University of California at San Diego. 1994.

5. Banks AJ. Diversity, group identity, and citizenship education in a global age. Educational Researcher. 2008; 37(3): 129-139.

6. Gorin E. Learning to understand: The role of language education in bridging the gap between multiculturalism and cosmopolitanism. A thesis submitted to the faculty of Wesleyan University. Middletown, Connecticut. 2012.

7. Gutmann A. "Unity and diversity in democratic multicultural education: Creative and destructive tensions," in Diversity and citizenship education: Global perspectives, ed. Banks J. A, 71-96. San Francisco: Jossey-Bass. 2004.

8. Appiah K. A. Cosmopolitanism: Ethics in a world of strangers. New York, NY: Norton. 2006.

9. Nussbaum M. Compassion: The basic social emotion. Social Philosophy and Policy. 1996; 13(1): 27-58.

10. Vinokur E, Agbaria A, Ergas O. Grounding cosmopolitan education: Theory and practice through the prism of particular culture, heritage and language. Philosophy of Education Society of Great Britain. Annual Conference. Oxford: New College. 2015.

11. Habermas J. "Struggles for recognition in the democratic constitutional state", in Multiculturalism, ed. Gutmann A, 105-107. New Jersey: Princeton University Press. 1994.

12. Mavroudis N, Bournelli P. The contribution of drama in education to the development of skills improving the interpersonal relations of multicultural classroom students. Journal of Educational Issues. 2019; 5(2): 42-57.

13. O'Farrell L. "The cultivation of creativity through theatre/drama in education", in Theatre and education in the center of the stage," ed. Govas N, 208-214. Athens: Panhellenic network for theatre in education. 2009. (in Greek)

14. Galazka A. Presentation: Creating emotional awareness through drama in the second language acquisition. BUKS. 2016; 61: 132-138.

15. Lembesi M. "Student, physical expression and theatre," in Theatre and intercultural education, ed. Drakopoulou K, 118-139. Athens: Daedalus. 2006. (in Greek)

16. Cohen L, Manion L, Morrison K. Research methods in education. London: Routledge. 2015.

17. Alsaawi A. A critical review of qualitative interviews. European Journal of Business and Social Sciences. 2014; 3(4): 149-156.

18. Danochristou M. Intercultural music education and teaching: The participatory coexistence of foreign secondary education students through the traditional music of their countries of origin. Doctoral thesis. School of Philosophy, Department 
of Music Studies, University of Athens. 2012. (in Greek)

19. Sextou P. A theatre in education study of multicultural understanding in Hellas. Youth Theatre Journal. 2006; 20(1): 77- 94.

20. Iosifidis T. Qualitative research methods in the social sciences. Athens: Review. 2008. (in Greek)

21. Altrichter H, Posch P, Somekh B. Introduction to critical reflection and action for teacher researchers. London: Routledge. 2005.

22. Feldman A, Altrichter H, Posch P, Somekh B. Teachers investigate their work: An introduction to action research across the professions. London: Routledge. 2018.

23. Cebrián G. "The role of the critical friend in supporting action for sustainability: exploring the challenges and opportunities," in Research and innovation in education for sustainable development, eds. Lambrechts W, Hindson J, 211226. Vienna: CoDes. 2016.

24. Katsarou E. Curriculum reform using active participatory research: The example of the Modern Greek language. Doctoral thesis. School of Philosophy, Department of Pedagogy, University of Athens. 1998. (in Greek)

25. Jacelon C. S, Imperio K. Participant diaries as a source of data in research with older adults. Qualitative Health Research. 2005; 15(7): 991-997.

26. Nadin S, Cassell C. The use of a research diary as a tool for reflexive practice: Some reflections from management research. Qualitative Research in Accounting \& Management. 2014; 3(3): 208-217.

27. Allport GW. The nature of prejudice. Cambridge, MA: Perseus Books. 1954.

28. Pettigrew TF, Tropp LR, Wagner U, Christ O. Recent advances in intergroup contact theory. International journal of intercultural relations. 2011 May 1;35(3):271-80.

29. Scacco A, Warren S. S. Can social contact reduce prejudice and discrimination? Evidence from a field experiment in Nigeria. Unpublished working paper. 2016.

30. Marotta V. Zygmunt Bauman: Order, straingerhood and freedom. Thesis Eleven. 2002; 70: 36-54.

31. Singh RJ. Examining xenophobic practices amongst university students. Alternation Special Edition. 2013; 7: 88-108.
32. Levi-Strauss C. Race and history. Gender and culture. Athens: Patakis. 2008. (in Greek)

33. Gkotovos EA. Education and otherness. Athens: Metaichmio. 2002. (in Greek)

34. Pantazis V, Marouli D. Roma children in primary school. Cultural enrichment or inhibitory factor? The perceptions of parents of primary school students in the prefecture of Ilia. The Social Sciences Step, 2011; 60: 121-136. (in Greek).

35. Dragona T. Stereotypes and prejudices. Keys and anti-keys. Ministry of Education: University of Athens. 2007.(in Greek)

36. Govaris C, Nioti N, Stamatis P. Prejudices and stereotypes in the multicultural kindergarten. Positions for their weakening from the point of view of intercultural education. Pedagogical Speech. 2003; 1: 7-20. (in Greek)

37. Maniatis P. "Communication and interaction in the multicultural class. Detecting stereotypes and their role in the educational process," in Issues of teaching and education in the multicultural school, eds. Katsarou E, Liakopoulou M, 511-554. Thessaloniki: A.P.Th. 2014. (in Greek)

38. Ribeiro GL. What is cosmopolitanism? Vibrant Virtual Brazilian Anthropology. 2005; 12(1): 1926.

39. Boal A. Theatre of the oppressed. London: Pluto Press. 2008.

40. Bhukhanwala F, Allexsaht-Snider M. Diverse student teachers making sense of difference through engaging in Boalian theatre approaches. Teachers and Teaching: Theory and Practice. 2012; 18(6): 675-691.

41. Govas N, Zonniou C. Theatrical pedagogical programs with forum theater techniques. Athens: Panhellenic Network for Theatre in Education \& Institution - Center for Arts \& Intercultural Education. 2010. (in Greek).

42. Saito H. Actor- network theory of cosmopolitan education. Journal of Curriculum Studies. 2010; 42(3): 333-351.

43. Alkistis. Black cow, white cow. Dramatic art in education and interculturalism. Athens: Topos. 2008. (in Greek). 